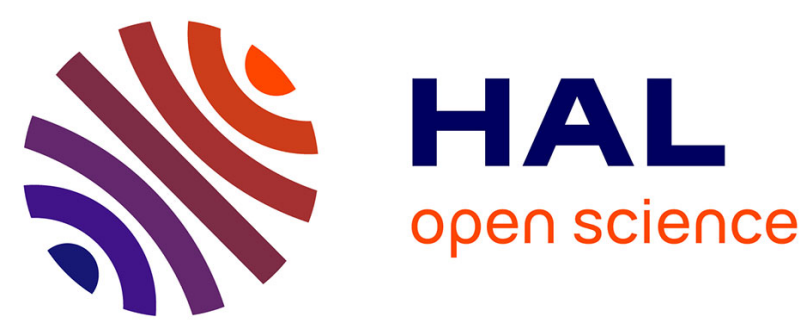

\title{
A trench study to assess transfer of pesticides in subsurface lateral flow for a soil with contrasting texture on a sloping vineyard in Beaujolais
}

\author{
X. Peyrard, L. Liger, C. Guillemain, V. Gouy
}

\section{- To cite this version:}

X. Peyrard, L. Liger, C. Guillemain, V. Gouy. A trench study to assess transfer of pesticides in subsurface lateral flow for a soil with contrasting texture on a sloping vineyard in Beaujolais. Environmental Science and Pollution Research, 2016, 23 (1), pp.14-22. 10.1007/s11356-015-4917-5 . hal-01684043

\section{HAL Id: hal-01684043 \\ https://hal.science/hal-01684043}

Submitted on 17 Jan 2018

HAL is a multi-disciplinary open access archive for the deposit and dissemination of scientific research documents, whether they are published or not. The documents may come from teaching and research institutions in France or abroad, or from public or private research centers.
L'archive ouverte pluridisciplinaire HAL, est destinée au dépôt et à la diffusion de documents scientifiques de niveau recherche, publiés ou non, émanant des établissements d'enseignement et de recherche français ou étrangers, des laboratoires publics ou privés. 


\title{
A trench study to assess transfer of pesticides in subsurface lateral flow for a soil with contrasting texture on a sloping vineyard in Beaujolais
}

\author{
X. Peyrard ${ }^{1}$, L. Liger ${ }^{1}$, C. Guillemain ${ }^{2}$, V. Gouy ${ }^{1}$ \\ ${ }^{1}$ : Diffuse agricultural pollution team \\ 2: Physico-chemical analysis of aquatic environment laboratory \\ Irstea, 5 rue de la Doua, CS 70077, 69626 Villeurbanne Cedex, France \\ Corresponding author: \\ $\mathrm{X}$. Peyrard \\ E-mail: xavier.peyrard@irstea.fr \\ Phone number: +33472208787 \\ Fax number: +33478477875 \\ Address: Irstea, 5 rue de la Doua, CS 70077, 69626 Villeurbanne Cedex, France
}

\begin{abstract}
Subsurface lateral flow in both texture-contrast soils and catchments with shallow bedrock is suspected to be a nonpoint source of contamination of watercourses by pesticides used in agriculture. As a case study, the north of the Beaujolais region (eastern France) provides a favorable environment for such contamination due to its agro-pedoclimatic conditions. Environments seen in the Beaujolais region include intense viticulture, permeable and shallow soils, steep hillslopes, and storms that occur during the periods of pesticide application. Watercourse contamination by pesticides has been widely observed in this region, and offsite pesticide transport by subsurface lateral flow is suspected to be involved in diffuse and chronic presence of pesticides in surface water. In order to confirm and quantify the potential role of such processes in pesticide transfer, an automated trench system has been designed. The trench was set up on a steep farmed hillslope in a texture-contrast soil. It was equipped with a tipping bucket flowmeter and an automatic sampler to monitor pesticide concentrations in lateral flow at fine resolution, by means of a flow-dependent sampling strategy. Four pesticides currently used in vine growing were studied to provide a range of mobility properties: one insecticide (chlorpyrifos-methyl) and three fungicides (spiroxamine, tebuconazole, and dimethomorph). With this system, it was possible to study pesticide concentration dynamics in the subsurface lateral flow, generated by substantial rainfall events following pesticide applications. The experimental design ascertained to be suitable method in which to monitor subsurface lateral flow and related transfer of pesticides.
\end{abstract}

\section{Keywords}

subsurface lateral flow; pesticide transfers; instrumented trench; hillslope hydrology; texture-contrast soil; flowdependent monitoring; viticulture 


\section{Introduction}

The use of pesticides in agriculture has led to extensive contamination of rivers in France (SOeS, 2011), and other countries (Schulz, 2004). The contaminations threaten fresh water resources and have been shown to directly impact aquatic ecosystem's diversity and biogeochemical functions (Schulz 2004; Schäfer et al. 2007). Both chronic and acute pesticide exposures have been shown to have impacts (Tlili et al. 2011). In order to reduce this contamination, it is necessary to identify and quantify the processes responsible for the migration of agrochemicals from farmland to surface water. Surface runoff and drainage that occur soon after pesticide application have been identified as major processes resulting in fast and intense contamination peaks in rivers (Bach et al. 2001; Louchart et al. 2001; Dabrowski et al. 2002; Brown et al. 2009). The role of subsurface lateral flow (SSLF) in the transport of pesticides into surface water has been much less studied. It is likely to generate chronic transfers in contexts of soils with a shallow impeding layer (Brown et al. 1995; Truman et al. 1998; Kahl et al. 2007). Indeed, when water infiltrating into the soil reaches a less permeable layer, it may accumulate if the incoming flow rate is higher than the permeability of this layer. Depending on the slope, this accumulated water may flow down to be collected in ditches and quickly reach rivers. This lateral diversion of water flow occurring in the soil is known as SSLF, throughflow, and interflow. Different types of soil layers impeding vertical infiltration have been reported: bedrock, fragipan, plough pan, argillic horizon of texture-contrast soils (Hardie et al. 2012; Tang et al. 2012).

As reviewed by Hardie et al. (2012), SSLF in hillslope hydrology has been investigated in the last decades, by mainly focusing on the understanding of streamflow generation, or agricultural soil management. SSLF transient occurrence in soils, as well as its spatiotemporal variability, requires custom monitoring techniques and protocols for measurement and sampling. Different instrumentations have been described in the literature to measure SSLF. For example, Lehman and Ahuja (1985) used a pit to intercept SSLF and a volumetric method with calibrated receptacles to measure discharge in a shallow bedrock context. Anderson and Burt (1977) as well as Ritsema et al. (1996) monitored SSLF with tensiometer networks in respectively shallow bedrock and impeding soil layer contexts. Whipkey and Ronald (1965), Webster (1966), and Weyman (1973) studied SSLF in a shallow bedrock context using multiple instruments: trenches, tensiometers and piezometers, and also used a manual volumetric method to measure SSLF discharge in trenches. McCord and Stephens (1987) monitored soil moisture content on a sandy hillslope that was subject to SSLF, but absent of any apparent impeding layer. Among these various methods, only trenches measured direct subsurface lateral water fluxes, and this measurement was mainly achieved by volumetric methods. Although SSLF in hillslope hydrology is well documented, the subsurface lateral transfer of pesticides has received less attention. It is a concern especially in mountainous and hilly farmlands, because they are usually underlain by shallow bedrock or fragipan. Kahl et al. (2007) measured pesticide transfers via SSLF in a shallow bedrock context with clay loam to clay soils - characterized by an important amount of macropores - occurring downslope on a litchi orchard in Northern Thailand. In this study, Kahl et al (2007) focused on macroporal SSLF which were collected by several wick samplers that were arranged on the upslope side of trenches. Macroporal SSLF discharge and pesticide concentrations were calculated by collecting sampling containers every one to two days. These authors observed simultaneous recoveries of tracers injected at different distances from the trenches during tracing experiments, and concluded that SSLF and related lateral pesticide transfers were caused by long preferential flows. In a highly 
weathered soil with both a moderate slope (0-8\%) and a shallow impeding layer, Truman et al. (1998) measured a large export of Fenamiphos in SSLF using a daily grab sampling strategy. However, these daily approaches could not capture the dynamics at the finer scale of a sub-event, which is necessary to accurately describe flow processes involved in pesticide transfers via SSLF. Brown et al. (1995) monitored discharge and isoproturon concentration in SSLF with a fine temporal resolution and a flow-dependent strategy in a drained clay soil. However, the specific contribution of SSLF could not be assessed because of its mixing with surface runoff in the experimental setup. Johnson et al. (1996) performed a thirty minute resolution monitoring of SSLF and isoproturon concentrations in a mole-drained clay soil. They showed that even without an apparent impeding layer, a substantial amount of pesticides could be transferred by lateral flow on a moderately sloped (5-10\%) heavy clay soil.

Finally, it appears that knowledge about pesticide transfers by lateral flow is still scarce and incomplete. As highlighted by Tang et al. (2012), additional field data in various agro-pedo-climatic contexts are needed to better assess the role of lateral flow in pesticide transfers. No field measurement of pesticide transfers via total SSLF (both macroporal and matrix flows) is available for sloping farmed soils with a shallow impeding layer. This gap is an issue, as such contexts are suspected to be very favorable for these transfers and because they may concern a large portion of agricultural soils (Phillips, 2004; Hardie et al. 2012).

Hence, the objectives of this paper are 1.) to describe an in situ experimental setup designed to monitor and sample the total SSLF to calculate induced pollutant fluxes, 2.) to verify the suitability of this design by obtaining measurements at the fine time scale of a SSLF event, 3.) to highlight the importance of short time step resolution monitoring strategy to study the dynamics of these transfers over a SSLF event. A sloping texture-contrast soil that is subject to subsurface lateral pesticide transfer, on a farmed plot in the Beaujolais region in France, has been used as a case study to reach these objectives.

\section{Material and methods}

\section{Site description}

The experimental site is located on a vineyard hillslope (longitude $46.16937 \mathrm{~N}$, latitude 4.64828 E) in the Morcille river watershed $\left(8 \mathrm{~km}^{2}\right)$ within the northern Beaujolais region (eastern France) (Rabiet et al. 2010). This watershed is representative of the climate, soils and agricultural practices of this region. The climate is temperate with Mediterranean and oceanic influences, having a mean annual rainfall of $859.3 \mathrm{~mm}$. The soils are mainly sandy, with the parent material being granite. More than $70 \%$ of the surface of the watershed is dedicated to vine growing, leading to a strong modification of the landscape and a large use of pesticides (annual organic pesticide application means in 2011 were $10.6 \mathrm{~kg} \cdot \mathrm{ha}^{-1}$, $5.3 \mathrm{~kg} \cdot \mathrm{ha}^{-1}$, and $0.14 \mathrm{~kg} \cdot \mathrm{ha}^{-1}$, respectively for fungicides, herbicides, and insecticides active ingredients) during the growing season. The slopes range from 10 to 35\% (average 20\%) on the $100 \mathrm{~m}$ (length) by $60 \mathrm{~m}$ (width) of the studied plot (Fig 1). In this watershed, cultivated soils have poor organic matter content of about $2 \%$ at the soil surface and less than $1 \%$ below ground surface (bgs) (Table 1). An increase in clay content is observed between the topsoil and the subsoil. The topsoil-subsoil transition is generally abrupt and is never more than $10 \mathrm{~cm}$ thick. This boundary is located between 30 and $80 \mathrm{~cm}$ bgs, depending on the location on the 
plot. The topsoil and subsoil saturated hydraulic conductivities $\left(\mathrm{K}_{\mathrm{s}}\right)$ have been determined with tension infiltrometer measurements and completed by the Müntz double-ring approach (Smith and Mullins, 1991) to better characterize macropore contribution (Table 1). $K_{\mathrm{s}}$ determined from the tension infiltrometer experiments were calculated by extrapolating the stationary infiltration flux measured at the following successive potentials: $-10,-3$, and $-0.5 \mathrm{~cm}$ of the water column (Ankeny et al. 1991; Reynolds and Elrick. 1991). For the topsoil, $\mathrm{K}_{\mathrm{s}}$ obtained with double ring infiltration experiments is at least one order of magnitude higher than with a tension infiltrometer. This difference could be explained by the relatively coarse texture of the topsoil; by the presence of small vine roots; and by worm holes (all having been visually confirmed). These measurements show that the subsoil $\mathrm{K}_{\mathrm{s}}$ can be two orders of magnitude lower than those in the topsoil. Furthermore it must be kept in mind that the observed topsoil $\mathrm{K}_{\mathrm{s}}$ are underestimations, since they do not take into account the direct effect of vine trunks and main roots on infiltration because of the impossibility to meet good experimental conditions at (or near) them.

Fig. 1 Plot and perched water table boundaries, surface contour, rain gauge, and experimental trench positions 


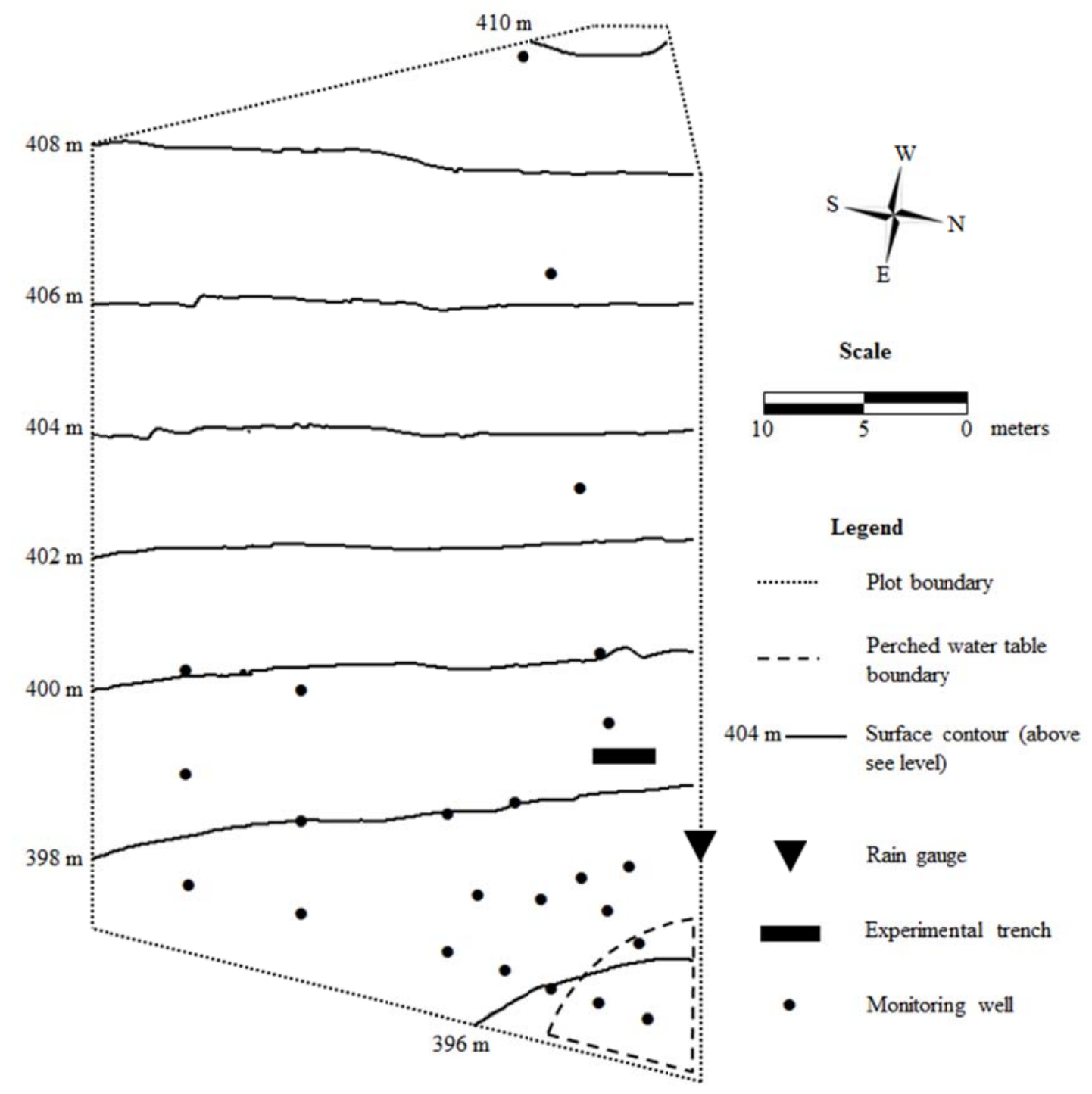

Table 1 Texture, organic matter content, and porosity of the topsoil and subsoil at trench location, and saturated conductivities $\left(K_{s}\right)$ of the topsoil and subsoil at four scattered locations in the plot, estimated either by double-ring infiltration or tension infiltrometers (when mentioned, $n$ is the number of measurements considered for the displayed mean value)

\begin{tabular}{|l|c|c|c|}
\cline { 3 - 4 } \multicolumn{2}{c|}{} & Sandy topsoil & Subsoil \\
\hline \multirow{2}{*}{ Texture } & Sand & $63 \%$ & $45 \%$ \\
\cline { 2 - 4 } & Loam & $25 \%$ & $35 \%$ \\
\hline
\end{tabular}




\begin{tabular}{|c|c|c|c|}
\hline & Clay & $12 \%$ & $20 \%$ \\
\hline \multicolumn{2}{|c|}{ Texture (FAO) } & Sandy loam & Loam to clay loam \\
\hline \multicolumn{2}{|c|}{ Organic matter } & $<1 \%$ & $<1 \%$ \\
\hline \multicolumn{2}{|c|}{ Porosity (Std.), $n=3$} & $0.41(0.035)$ & $0.36(0.009)$ \\
\hline $\begin{array}{c}\text { Mean } \mathrm{K}_{\mathrm{s}} \\
(\min -\max )\end{array}$ & $\begin{array}{c}\text { Tension } \\
\text { infiltrometer }\end{array}$ & $\begin{array}{c}1.06 \times 10^{-6} \mathrm{~m} . \mathrm{s}^{-1} \\
\left(6.27 \times 10^{-7}-2.22 \times 10^{-6} \mathrm{~m} . \mathrm{s}^{-1}\right) \\
n=6\end{array}$ & $\begin{array}{c}2.07 \times 10^{-7} \mathrm{~m} . \mathrm{s}^{-1} \\
\left(4.31 \times 10^{-8}-1.04 \times 10^{-6}\right) \\
n=7\end{array}$ \\
\hline $\begin{array}{c}\text { Mean } \mathrm{K}_{\mathrm{s}} \\
(\min -\max )\end{array}$ & $\begin{array}{l}\text { Double ring } \\
\text { infiltrometer }\end{array}$ & $\begin{array}{c}\left.4.33 \times 10^{-5}{\mathrm{~m} . \mathrm{s}^{-1}}^{-4} \mathrm{~s}^{-1}\right) \\
\left(7.07 \times 10^{-6}-2.31 \times 10^{-4} \mathrm{~m} . \mathrm{s}^{-1}\right. \\
n=4\end{array}$ & $\begin{array}{c}4.59 \times 10^{-7} \mathrm{~m} . \mathrm{s}^{-1} \\
\left(3.09 \times 10^{-8}-6.81 \times 10^{-6} \mathrm{~m} . \mathrm{s}^{-1}\right) \\
n=2\end{array}$ \\
\hline
\end{tabular}

The studied plot is hydrologically isolated from the surrounding farmed plots at its north, west, and south boundaries. Incoming surface runoff is deflected by a pipe network and SSLF coming from the west plot is stopped by a bank, and then evacuated by the surface pipe network. Subsurface water level monitoring (2013-2014) by piezometers located next to the west boundary, demonstrated that no water had crossed it. The north and south boundaries were not physically isolated because the SSLF stream lines obtained from monitoring wells proved to have a steady direction similar to the surface gradient (i.e. west-east), ensuring minimal water exchanges with these adjacent plots.

Instrumentation: wells, rain gauge, trench, automatic sampler and sampling strategy

In 2012, 18 monitoring wells were set up on the plot (Fig 1) in holes dug down to the boundary between the sandy topsoil and the more clay-rich subsoil. Monitoring wells were $4 \mathrm{~cm}$ in diameter and $1 \mathrm{~m}$ long full PVC tubes, which were slotted on the $20 \mathrm{~cm}$ base of their casing. Annular space was filled with gravel and cemented with bentonite at the soil surface to avoid runoff of flow inside. Six monitoring wells were equipped with water level dataloggers. The other wells were regularly monitored manually with a contact gauge during and after rainfall events.

Data from the monitoring wells highlighted the presence of a temporary perched water table, located in the downslope part of the plot (Fig 1). In the upslope area, monitoring wells revealed the existence of a very transient saturation of the topsoil. Both this transient saturation and the presence of the perched water table were suspected to account for subsurface lateral flows (data not shown) generated in the plot and gathering downslope. In March 2014, a trench (Fig 1) was set up to collect the subsurface lateral flow occurring above the impeding subsoil (Fig 2). The trench was $3 \mathrm{~m}$ long, $0.6 \mathrm{~m}$ wide and $0.8 \mathrm{~m}$ deep (the subsoil was found between 50 and $60 \mathrm{~cm}$ bgs during the excavation). In order to collect the flow seeping from the permeable topsoil, two $1.5 \mathrm{~m}$ long zinc gutters with a "V" profile were fitted in the subsoil on the upslope side of the trench. When fitted into the soil, the two gutters were bent and soldered together, to provide an outlet at middle of the trench. Water flows through this outlet, which was a full PVC cylinder fitted hermetically through the gutters. The cylinder was perforated on its upper part (to allow the water to flow inside) and embedded into a V-shaped PVC pipe acting as a siphon to ensure a minimal sampling

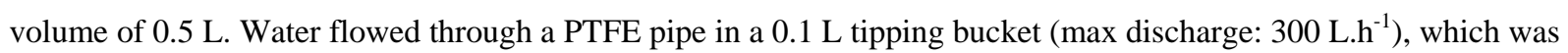
wired to a CR800 datalogger (Campbell Scientific), and was finally drained downslope through an underground pipe. On the upslope side of the trench, the soil is propped with fiberglass netting supported by a hard steel grating, while the other sides of the trench were held with wood supports. The materials of the elements that intended to be in 
contact with the pesticide solution were selected to minimize potential substance adsorption for an acceptable cost. The whole structure of the trench was kept in place by a wooden frame, and steel plates covered the surface to avoid rainfall entry and to allow tractor passage. Upslope from the trench, a plastic edging impeded the entrance of surface runoff into the trench. Precipitations were measured using a tipping bucket rain gauge wired to the CR800 datalogger.

Fig 2 Inside view of the trench showing the steel grate (top right), the fiber glass netting (right), the zinc gutter (from bottom right to top center), the PVC outlet pipe (center), the V-shaped PVC pipe (center, below the low-point outlet), the sampling pipe (from top to center, entering into the V-shaped PVC pipe through the PVC outlet), and the trench tipping bucket (center left). The upslope side is on the right and water evacuation is below the tipping bucket 


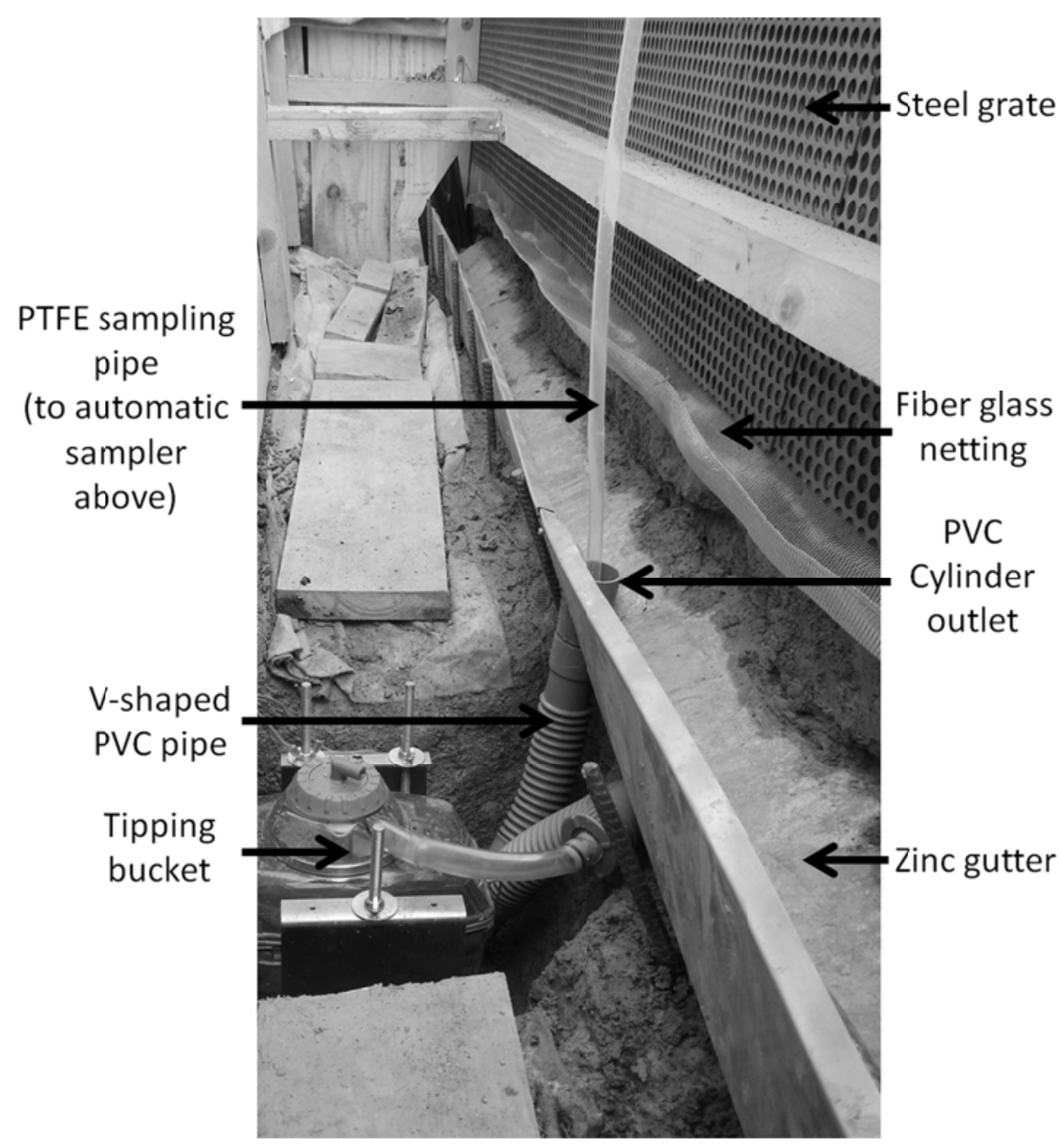

The CR-800 datalogger records total ticks of both trench and rain gauge tipping buckets every $15 \mathrm{~s}$ and is wired to an automatic sampler located at the soil surface. Automatic samples are taken via a PTFE pipe immersed into the Vshaped PVC pipe (Fig 2).

A flow-dependent monitoring strategy has been used to sample SSLF for pesticide concentration measurement. SSLF discharge is calculated every minute using a 3-h moving average.

\section{Estimated source area}

Given the hydrologic isolation of the plot (see above) and the regularity of the measured hydraulic gradient upslope from the trench position (from west to east), it can be assessed that the trench intercepts approximatively $3 \mathrm{~m}$ of the $60 \mathrm{~m}$ long cross section (north-south) of the plot. This roughly represents $1 / 20^{\text {th }}$ of the total SSLF produced by the part of the plot upslope from the trench. 
An alternative strategy that isolates a subplot to better control the source area has been studied. This strategy was rejected because it induces flow modifications (due to local soil structure destruction) and it implies cutting vine roots while they are suspected to play a major role in subsurface lateral preferential flows.

$\underline{\text { Pesticide application and characteristics, sample treatment and analysis }}$

Four pesticides currently used in vine growing were studied: one insecticide (chlorpyrifos-methyl) and three fungicides (spiroxamine, tebuconazole, and dimethomorph). They were applied at different rates and dates (Table 2) by the farmer using a tractor with a canon sprayer.

Table 2 Studied pesticides application dates and rates

\begin{tabular}{|c|c|c|c|c|}
\hline & \multicolumn{4}{|c|}{ Application rates $\left(\mathrm{g} . h a^{-1}\right.$ ) } \\
\hline Application dates & Chlopyrifos-methyl & Spiroxamine & Tebuconazole & Dimethomorph \\
\hline $2014 / 05 / 18$ & 337.5 & 0 & 107.5 & 0 \\
\hline $2014 / 05 / 29$ & 0 & 0 & 107.5 & 0 \\
\hline $2014 / 06 / 11$ & 0 & 0 & 107.5 & 0 \\
\hline $2014 / 06 / 27$ & 0 & 300 & 0 & 226 \\
\hline $2014 / 07 / 16$ & 337.5 & 300 & 0 & 0 \\
\hline
\end{tabular}

These pesticides were selected because of their range of physico-chemical properties and mobility (Table 3), and also because they are an ecological concern in the Morcille watershed due to their widespread use and detection in the Morcille River.

Table 3 Studied substance characteristics and analytical limits of quantifications. $\mathrm{K}_{\mathrm{oc}}$, solubility and field DT50 values come from the SIRIS database (Ineris, 2012)

\begin{tabular}{|c|c|c|c|c|}
\hline & Chlopyrifos-methyl & Spiroxamine & Tebuconazole & Dimethomorph \\
\hline $\mathrm{K}_{\mathrm{oc}}\left(\mathrm{mL} . \mathrm{g}^{-1}\right)$ & 4645 & 1947 & 1022 & 408 \\
\hline Solubility in water at $20^{\circ} \mathrm{C}\left(\mathrm{mg}^{-\mathrm{L}^{-1}}\right)$ & 2.74 & 405 & 36 & 290 \\
\hline Field DT50 (days) & 3 & 24.5 & 31 & 42.1 \\
\hline Limit of quantification $\left(\mu{\left.\mathrm{g} . \mathrm{L}^{-1}\right)}\right.$ & 0.004 & 0.0002 & 0.0005 & 0.002 \\
\hline
\end{tabular}

The automatic sampler has been used in a 24-glass bottle configuration and samples were kept cool (below $10^{\circ} \mathrm{C}$ for a maximum of $24 \mathrm{~h}$ ) with ice blocks in the sampler. During their transport to the laboratory, samples were kept below $5^{\circ} \mathrm{C}$ in a dark and cool box. They were filtered using $0.7 \mu \mathrm{m}$ glass fiber filter $(\mathrm{GF} / \mathrm{F})$ with a vacuum filtration glass system. Filtered samples were frozen and stored at $-18^{\circ} \mathrm{C}$ prior to analysis. Sample freezing has been shown not to affect studied pesticide concentrations (Margoum et al. 2011). The pesticide concentrations were measured by solid phase extraction (Oasis HLB 3 cc 60 mg cartridges, Waters) followed by liquid chromatography coupled with tandem mass spectrometry (SPE-LC-MS/MS). Extractions were performed with an Autotrace 280 Dionex (Thermo Scientific). Cartridges were pre-conditioned using $3 \mathrm{~mL}$ of methanol, then with $3 \mathrm{~mL}$ of ultrapure water, and finally with $3 \mathrm{~mL}$ of acetonitrile. After the percolation of the $250 \mathrm{~mL}$ filtered sample, the cartridge was washed using $3 \mathrm{~mL}$ of ultrapure water and eluted with $6 \mathrm{~mL}$ of acetonitrile. Finally, the collected elution solvent was evaporated under a nitrogen stream for $30 \mathrm{~min}$, and the dried extract was dissolved in $250 \mu \mathrm{L}$ solution of ultrapure water and acetonitrile 
(80/20). Chromatographic separation was performed with a Waters HSS T3 column (C18 $1.7 \mu \mathrm{m}, 100 \times 2.1 \mathrm{~mm})$ at $40^{\circ} \mathrm{C}$, injection volume was $10 \mu \mathrm{L}$. Acetonitrile and ultrapure water both with $0.1 \%(\mathrm{v} / \mathrm{v})$ formic acid were used in an analytical gradient of 15 min. Limits of quantification are given in Table 3 for all studied substances, and analytical uncertainties varied from 20 to $60 \%$ at the quantification level, depending on the compound. Concentrations of undetected compounds are considered to be zero and concentrations of unquantified detected compounds are considered to be equal to half their respective limit of quantification.

\section{Results}

\section{$\underline{\text { Subsurface lateral flow }}$}

Although the monitoring started at the beginning of March 2014, no SSLF was recorded before July, due to low precipitation during spring of 2014 in the Beaujolais region (Fig 3). Three events were measured in July 2014 (Fig 3). Event A (6-16 July) was triggered by a $29 \mathrm{~mm}$ cumulative rainfall in its first part (6-9 July), and by a $22 \mathrm{~mm}$ cumulative rainfall in its second part (9-16 July). Event B (21-25 July) was triggered by a 34 mm cumulative rainfall, and event C (30 July-2 August) by a $31 \mathrm{~mm}$ cumulative rainfall.

Between the beginning of March and the end of June 2014, the soil was dry and the cumulative rainfall amounts were lower than during the July events. Moreover, the main features of the previous rainfall events (10, 23, and 28 June) were high rainfall intensities, leading a large part of rainwater to flow over the soil surface rather than to infiltrate.

Fig 3 Cumulative rainfall, SSLF 3-h averaged discharge from mid-May 2014 to the 4 August, 2014, application dates, and A-B-C SSLF event periods 


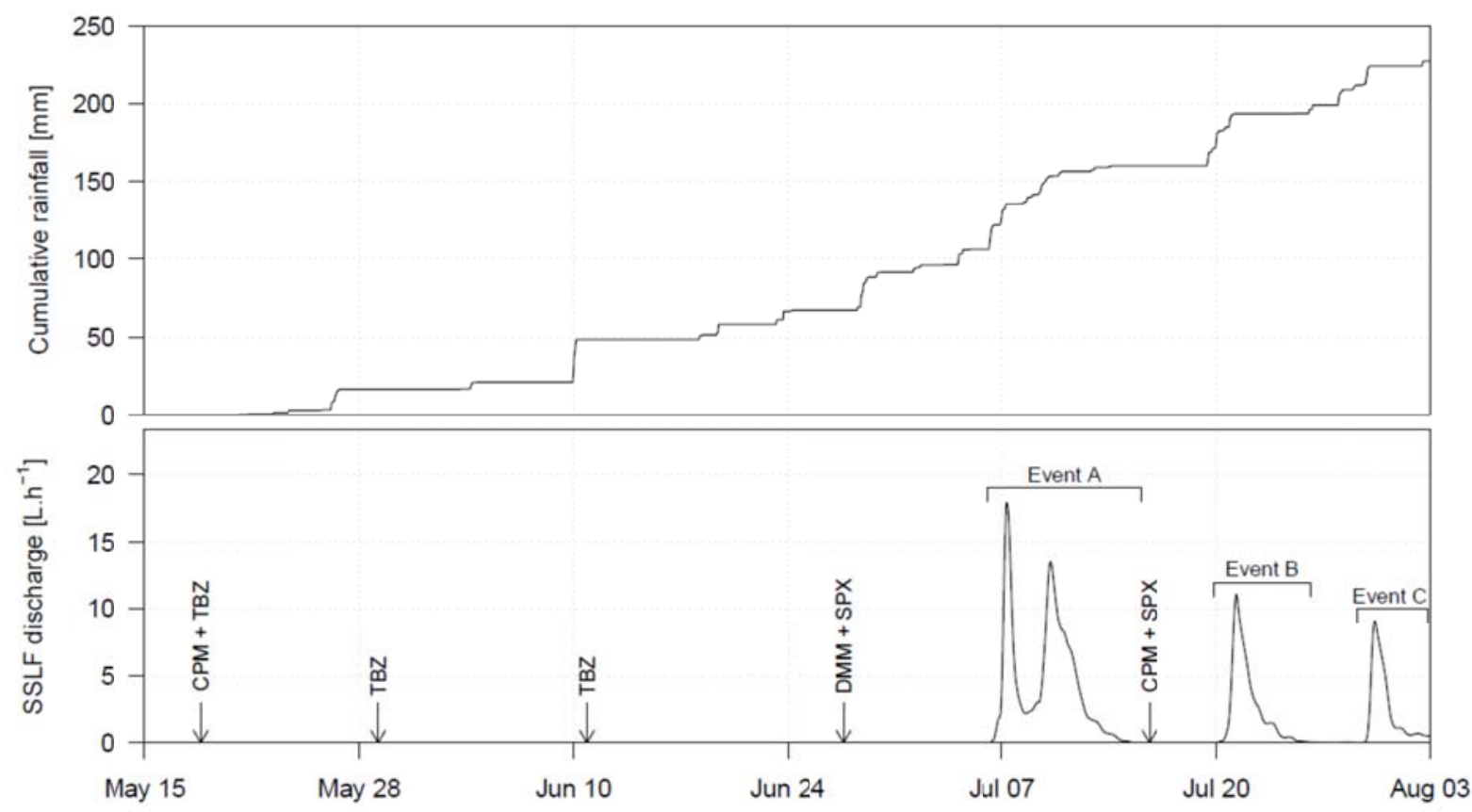

Pesticide dynamics in SSLF at event scale

The monitoring device successfully sampled SSLF 85 times during all three July events with the flow-dependent strategy. Several samplings failed at the beginning of the increased discharge (event A, first part) due to technical problems, and at the middle of the drop in the discharge (event A, first part) because of unexpectedly high SSLF discharge level compared to our initial forecasts. Among the eighty five samples, forty nine were chosen according to their occurrence into the flow shape and the pesticides were analyzed. The concentrations of each studied substance cover at least one order of magnitude over the whole period, proving their high temporal variability in SSLF.

During event B, at the beginning of the increase of SSLF, pesticide concentrations immediately raised and then rapidly dropped while SSLF discharge increased. A similar behavior is observed during event C, except for chlorpyrifos-methyl, which was no longer quantified. Smaller variations in pesticide concentrations were observed during the increase of the discharge in the first part of event A, maybe because this first raise of SSLF could not be sampled in its entirety. No significant peak in pesticide concentrations was observed during the second peak of SSLF discharge in event A, except for a few samples and chlorpyrifos-methyl concentrations.

Fig 4 SSLF 3-h averaged discharge and chlorpyrifos (CPM), spiroxamine (SPX), tebuconazole (TBZ), and dimethomorph (DMM) measured concentrations in SSLF from 1 July to 4 August, 2014, and A-B-C SSLF event periods 


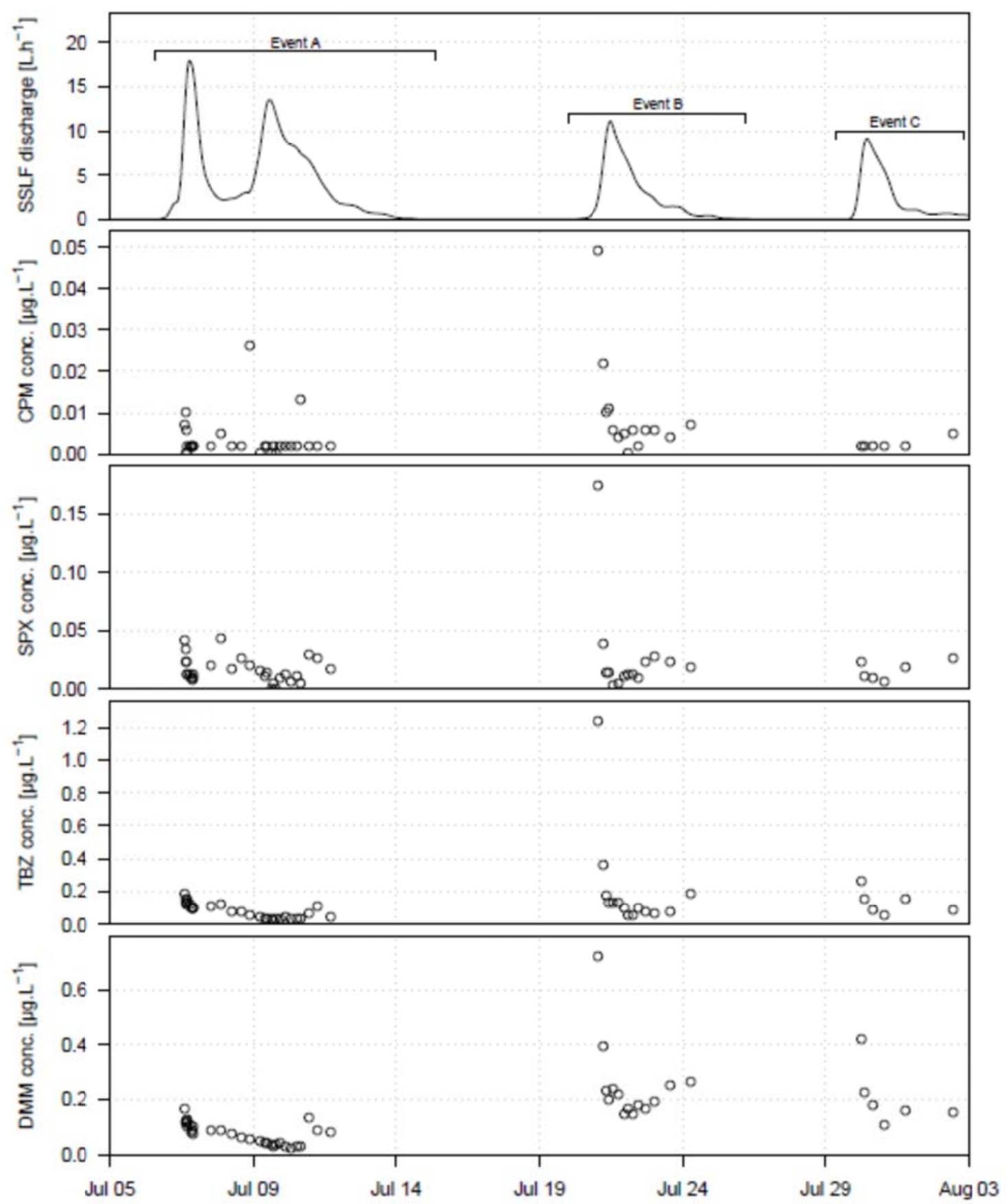

From all analyzed samples in July, it was possible to order the studied pesticides according to their mean concentrations (Fig 4) over the total period of observation: dimethomorph mean concentration was only slightly higher than that of tebuconazole. Both dimethomorph and tebuconazole concentrations were clearly higher than the spiroxamine concentration, and all of them were considerably higher than the chlorpyrifos-methyl mean concentration. 
Fig 5 Chlorpyrifos-methyl (CPM), spiroxamine (SPX), tebuconazole (TBZ), and dimethomorph (DMM) concentrations box plots

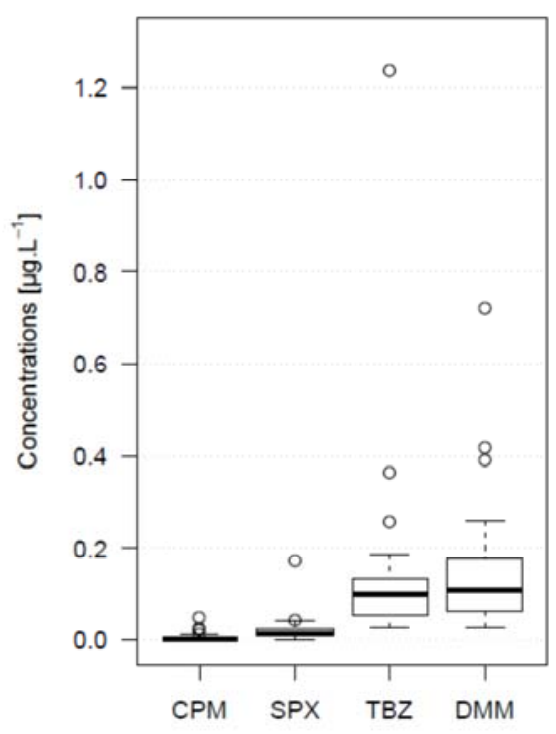

\section{Discussion}

\section{$\underline{\text { Subsurface lateral flow }}$}

SSLF monitoring with a tipping bucket, as done in this study, appears to be especially efficient: both low and high discharge levels were precisely measured because of their consistency with the tipping bucket range, and SSLF discharge variations are described at a fine resolution. The distance travelled by SSLF between its collection, into the gutters, and discharge measurement, has been minimized in order to be as representative as possible of the actual collected flow. The monitoring highlighted the great dependency of SSLF triggering on previous rainfall amount and pattern, which is consistent with the literature (Hardie et al. 2012). However, very intense rainfall favoring surface runoff did not imply that lateral flow would occur, even if cumulative rainfall exceeds $20 \mathrm{~mm}$. This observation suggests that instead of cumulated rainfall, cumulative infiltration would be more relevant to predict the trigger of SSLF. In any case, the number of observations in this plot is currently low and more joint measurements of SSLF and rainfall events are required to better understand the determinism of these processes.

\section{Pesticide dynamics in SSLF at event scale}

In the studied case, the representativeness of SSLF fast variations in the sampling was ensured by the small distance between SSLF collection and sampling, and by the optimization of the flow-dependent sampling strategy. The design successfully monitored the dynamics of pesticide concentrations on small discharge variation scales; in particular, the abrupt increases in concentrations at the beginning of the events were highlighted. Previously, Johnson et al. (1996) have observed early-event high concentrations in SSLF with isoproturon, but in a more limited variation range. They could be attributed to preferential flows through macropores or cracks, which were also likely to occur 
in our study due to the presence of many living and degrading vine roots developed horizontally above the impeding layer. Pit studies undertaken after rainfall events revealed that these roots actually conducted lateral flow preferentially, compared to matrix flow. According to Wallach et al. (1992), another phenomenon that could play a role in the early-event pesticide concentration drop is the availability of pesticides for infiltration, which has been verified to be higher at the beginning of an event (initial pesticide concentration being in equilibrium in the soil solution) and to decrease by dilution and according to pesticide kinetics of desorption. Dynamics and concentrations of the different monitored pesticides are related to their respective adsorption coefficient and half-life in the field. This is consistent with the SSLF tracing experiments performed by Kahl et al. (2007), who noticed a greater mass recovery for pesticides with lower adsorption coefficients.

\section{Conclusions}

High temporal variability of transfers of four pesticides via SSLF in a texture-contrast soil was shown through a suitable experimental setup and associated sampling strategy. The instrumented trench measured SSLF discharge range and variations at fine resolution using a tipping bucket connected to a datalogger. A combination of low adsorptive material collecting SSLF with a V-shaped PVC pipe ensured representative sampling of SSLF. During three SSLF events, flow-dependent sampling revealed the transfer dynamics of one insecticide (chlorpyrifos-methyl), and three fungicides (dimethomorph, spiroxamine, tebuconazole). Monitoring pesticides with various physicochemical properties underlined a concentration hierarchy in accordance with their adsorption coefficients and halflives in the field. During the three events monitored, lateral transfer behavior showed the possible occurrence of preferential flow processes and resulting pesticide transfers, which is in concordance with pre-existing literature on SSLF. Fine-resolution monitoring of more events is necessary to confirm or contradict observed tendencies and to identify more clearly related mechanisms and influence factors.

The experimental setup was used in 2014 and 2015 to better understand lateral pesticide transfers on the study site. An SSLF tracing experiment would give the opportunity to further explore SSLF pathways and investigate pesticide fluxes and rates of transfer, in relation to their physico-chemical properties. Moreover, a coupled monitoring of subsurface lateral transfers and surface runoff transfers at the event, seasonal, and yearly scales would provide more information on these scarcely studied processes.

\section{Acknowledgements}

The financial support of the Water Agency Rhône Méditerranée \& Corse is acknowledged. The authors thank M. Letey and C. Dutremble for their contribution to the field work; P. Bouland, vinegrower, for allowing our research on his farmed plot, and the staff of the "diffuse agricultural pollution” team for their help during the digging of the trench.

\section{Conflict of interest}


The authors declare that they have no conflict of interest.

\section{References}

Anderson MG, Burt TP (1977) Automatic monitoring of soil-moisture conditions in a hillslope spur and hollow. Journal of Hydrology 33:27-36. doi:10.1016/0022-1694(77)90096-8

Ankeny MD, Ahmed M, Kaspar TC, Horton R (1991) Simple field method for determining unsaturated hydraulic conductivity. Soil Sci Soc Am J 55:467-470

Bach M, Huber A, Frede HG (2001) Input pathways and river load of pesticides in Germany--a national scale modeling assessment. Water science and technology: a journal of the International Association on Water Pollution Research 43:261-268

Brown CD, Hodgkinson RA, Rose DA, Syers JK, Wilcockson SJ (1995) Movement of pesticides to surface waters from a heavy clay soil. Pesticide Science 43:131-140. doi:10.1002/ps.2780430206

Brown CD, van Beinum W (2009) Pesticide transport via sub-surface drains in Europe. Environmental pollution 157:3314-3324. doi:10.1016/j.envpol.2009.06.029

Dabrowski JM, Peall SKC, Reinecke AJ, Liess M, Schulz R (2002) Runoff-related pesticide input into the Lourens River, South Africa: basic data for exposure assessment and risk mitigation at the catchment scale. Water, Air, \& Soil Pollution 135:265-283. doi:10.1023/A:1014705931212

Hardie MA, Doyle RB, Cotching WE, Lisson S (2012) Subsurface lateral flow in texture-contrast (duplex) soils and catchments with shallow bedrock. Applied and Environmental Soil Science 2012:10. doi:10.1155/2012/861358

Ineris (2012) SIRIS-Pesticides, base de données substances actives 2012. http://www.ineris.fr/sirispesticides/bdd_siris_pesticides. Accessed 23 January 2015 (in French)

Johnson AC, Haria AH, Bhardwaj CL, Williams RJ, Walker A (1996) Preferential flow pathways and their capacity to transport isoproturon in a structured clay soil. Pesticide Science 48:225-237

Kahl G, Ingwersen J, Nutniyom P, Totrakool S, Pansombat K, Thavornyutikarn P, Streck T (2007) Micro-trench experiments on interflow and lateral pesticide transport in a sloped soil in northern Thailand. Journal of environmental quality 36:1205-1216. doi:10.2134/jeq2006.0241

Lehman OR, Ahuja LR (1985) Interflow of water and tracer chemical on sloping field plots with exposed seepage faces. Journal of Hydrology 76:307-317. doi:10.1016/0022-1694(85)90139-8

Louchart X, Voltz M, Andrieux P, Moussa R (2001) Herbicide transport to surface waters at field and watershed scales in a Mediterranean vineyard area. Journal of environmental quality 30:982-991

Margoum C, Guillemain C, Biaudet H, Lepot B (2011) Stabilité des substances organiques dans les échantillons d'eau entre le prélèvement et la prise en charge analytique. Etat de l'art et exemples d'études. Cemagref, Ineris (in French)

McCord JT, Stephens DB (1987) Lateral moisture flow beneath a sandy hillslope without an apparent impeding layer. Hydrological Processes 1:225-238. doi:10.1002/hyp.3360010302

Phillips JD (2004) Geogenesis, pedogenesis, and multiple causality in the formation of texture-contrast soils. Catena 58:275-295. doi:10.1016/j.catena.2004.04.002

Rabiet M, Margoum C, Gouy V, Carluer N, Coquery M (2010) Assessing pesticide concentrations and fluxes in the stream of a small vineyard catchment--effect of sampling frequency. Environmental pollution 158:737-748. doi:10.1016/j.envpol.2009.10.014

Reynolds WD, Elrick DE (1991) Determination of Hydraulic Conductivity Using a Tension Infiltrometer. Soil Sci Soc Am J 55:633-639

Ritsema CJ, Oostindie K, Stolte J (1996) Evaluation of vertical and lateral flow through agricultural loessial hillslopes using a two-dimensional computer simulation model. Hydrological Processes 10:1091-1105. doi:10.1002/(sici)1099-1085(199608)10:8<1091::aid-hyp414>3.0.co;2-j

Schafer RB, Caquet T, Siimes K, Mueller R, Lagadic L, Liess M (2007) Effects of pesticides on community structure and ecosystem functions in agricultural streams of three biogeographical regions in Europe. The Science of the total environment 382:272-285. doi:10.1016/j.scitotenv.2007.04.040

Schulz R (2004) Field studies on exposure, effects, and risk mitigation of aquatic nonpoint-source insecticide pollution: a review. Journal of environmental quality 33:419-448

Smith KA, Mullins CE (1991) Soil Analysis: Physical Methods. Marcel Dekker, New York

SOeS (Service français d'Observation et des Statistiques), 2011. Bilan de présence des micropolluants dans les milieux aquatiques continentaux, Période 2007-2009. In Études \& documents du Commissariat général du développement durable, Service de l'observation et des statistiques : $n^{\circ} 54$ octobre 2011. ISBN : 978-2-11- 
099419-6. www.statistiques.developpement-durable.gouv.fr, 60 p. Accessed 23 January 2015 (in French)

Tang X, Zhu B, Katou H (2012) A review of rapid transport of pesticides from sloping farmland to surface waters: processes and mitigation strategies. Journal of environmental sciences 24:351-361

Tlili A, Montuelle B, Berard A, Bouchez A (2011) Impact of chronic and acute pesticide exposures on periphyton communities. The Science of the total environment 409:2102-2113. doi:10.1016/j.scitotenv.2011.01.056

Truman CC, Leonard RA, Johnson AW (1998) Fenamiphos transport, transformation, and degradation in a highly weathered soil. Transactions of the ASAE 41:663-671

Webster R (1966) The measurement of soil water tension in the field. New Phytologist 65:249-258. doi:10.1111/j.1469-8137.1966.tb06357.x

Weyman DR (1973) Measurements of the downslope flow of water in a soil. Journal of Hydrology 20:267-288

Whipkey RZ (1965) Subsurface stormflow from forested slopes. International Association of Scientific Hydrology 10:74-85. doi:10.1080/02626666509493392 